\title{
Caryatin and 3'-O-methylcaryatin contents in edible yams (Dioscorea spp.)
}

\author{
Benjamin Fel a, bc, d, Anne Baudouin a, b, e, Fabienne Fache a, b, f, Sonia Czarnes a, bc, d, Vincent Lebot ${ }^{\mathrm{g}}$, \\ Laurent Legendre a, bcd, [
}

\author{
a Université de Lyon, F-69622, Lyon, France \\ ${ }^{\mathrm{b}}$ Université Lyon 1, Villeurbanne, France \\ ${ }^{\mathrm{c}}$ CNRS, UMR5557, Ecologie Microbienne, Villeurbanne, France \\ d INRA, UMR1418, Villeurbanne, France \\ ' Centre Commun de RMN, France \\ ${ }^{\mathrm{f}}$ CNRS, UMR 5246, Institut de Chimie et Biochimie Moléculaires et Supramoléculaires, Villeurbanne, France \\ ${ }^{g}$ CIRAD-BIOS, UMR AGAP, PO Box 946, Port Vila, Vanuatu
}

\section{ARTICLEINFO}

\section{Keywords:}

Antioxidant

Antimicrobial

Flavonol

Caryatin

3'-O-methylcaryatin

Dioscorea

Yam

\begin{abstract}
A B S T R A C T
The genus Dioscorea hosts a large number of yam species used medicinally and as a staple food by millions of people in tropical countries. All yams share a high antioxidant activity that correlates with their total phenolics contents. However, knowledge of edible species antioxidant phenolics remains incomplete. Bioassay-guided fractionation of the tubers of a yam species with high total phenolics content, D. nummularia, led to the isolation of two flavonols, caryatin and 3'-O-methyl caryatin, contributing over $92 \%$ of a stable methanol extract of the tuber in this species. Their structures were determined by high resolution mass spectrometry (HRMS), nuclear magnetic resonance (NMR) and a synthesized authentic sample. They displayed no bacterial toxicity. Their content was estimated in the tubers and bulbils of 411 landraces and hybrids belonging to eight food yam species using high performance-thin layer chromatography (HP-TLC). These were found to be highly variable at the intra- and interspecific levels to reach up to 1030 and $457 \mu \mathrm{g} / \mathrm{g}$ DW respectively and added up to contents of already described antioxidant phenolics. This study provides additional understanding of the health benefits of a yam diet and constitutes the first phytochemical analysis of D. nummularia.
\end{abstract}

\section{Introduction}

With approximately 640 species, the genus Dioscorea L. (Dioscoreaceae, Dioscoreales) is incredibly diverse (Govaerts et al., 2007) and economically important. It hosts a large panel of edible yam species that constitute the major staple food of millions of people in tropical regions of Africa, Caribbean, South-East Asia and the numerous small islands of Oceania (Asiedu and Sartie, 2010). The most important edible species are D. alata L., D. bulbifera L., D. cayenensis Lam., D. dumetorum (Kunth) Pax, D.esculenta (Lour.) Burkill, D.japonica Thunb.,D.nummularia Lam., D. oppositifolia L., D. pentaphylla L., D. rotundata Poir., and D. trifida L. About $98 \%$ of the 70 Mt of yam produced in 2018 on 9 Mha originated from West Africa (FAOSTAT, 2020), and mainly from the two Guinea yams (D. rotundata and D. cayenensis). However, several species from Asia-Oceania exhibit attractive agronomic performances, high yields and interesting organoleptic qualities. Among them D. alata has the most ancient domestication history, is cultivated on the largest geographical scale and is gaining in importance in West Africa (Lebot, 2020).

A large body of work has stressed the numerous health benefits of a yam diet. Besides starch, all cultivated yams are a good source of proteins, fibers, potassium, carotenoids, polyphenols and vitamins $\mathrm{C}$ and $\mathrm{E}$ (Champagne et al., 2010, 2011; Chandrasekara and Kumar, 2016; Lebot et al., 2019). More specific health benefits also exist as a yam diet has been shown to reduce cognitive deterioration and brain lipid peroxidation in mice (Chan et al., 2004) as well as type- 2 diabetes mellitus induced by a high fat diet (Ma et al., 2020). Many wild yams are used medicinally (Dutta, 2015; Mohan et al., 2011; Salehi et al., 2019) and their bioactive substances are as diverse as the afflictions they cure. These include allantoin, an hydantoin with stomach-protecting, antitumoral and anti-diabetic properties (Go et al., 2015; Lee et al., 2011; Liu et al., 2016; Ma et al., 2020). Steroidal saponins such as dioscin and diosgenin contribute to breast cancer protection (Aumsuwan et al., 2016), and to the antioxidative, hypolipidemic (Son et al., 2007), anticholesterolemia (Cayen and Dvornik, 1979), antifungal (Cho et al.,

\footnotetext{
${ }^{\square}$ Corresponding author at: University of Lyon, Laboratory of Microbial Ecology, 43 boulevard du 11 novembre 1918, 69622 Villeur banne Cedex 2, France.

E-mail address: laurent.legendre@univ-lyon1.fr (L. Legendre).
} 
2013) and renal injury protection (Zhang et al., 2017) properties of yam extracts. All analyzed yam species contain significant quantities of bioactive phenolic compounds (Champagne et al., 2011; Chandrasekara and Kumar, 2016). For example, kaempferol-3,5dimethyl ester was shown to contribute to the anti-tumoral activity of ethanol extracts of the Chinese medicinal yam, D. bulbifera (Gao et al., 2002). Compared to other medicinal plant species, medicinal yams are a noted source of antioxidants that have been suggested to contribute to many of their therapeutic benefits (Adeniran et al., 2020; Gao et al., 2002; Liu et al., 2016; Song et al., 2010). Following the screening of 56 selected Chinese medicinal plants, D. bulbifera ranked among the four best sources of antioxidants (Song et al., 2010).

Staple food yams have received less attention with regard to their phytochemical content although some species such as D. bulbifera may be medicinal predicaments and food contributors (Guan et al., 2017; Kundu et al., 2020). It has nevertheless been established that food and medicinal yams share a high antioxidant activity and that this soughtafter property is associated with the health benefits of a yam diet (Chandrasekara and Kumar, 2016). Food yams such as D. alata (Chen and Lin, 2007; Cornago et al., 2011; Dilworth et al., 2012), D. esculenta (Cornago et al., 2011) and D.japonica (Hsu et al., 2011) possess high 1,1-diphenyl-2-picryllhydrazyl (DPPH) radical scavenging activity. These studies reported good correlations between the radical scavenging activity and the total phenolics contents of medicinal and food yam extracts, in agreement with the current knowledge on the high antioxidant activity of plant phenols and polyphenols (Shahidi and Ambigaipalan, 2015). However, knowledge on the phenolic compounds of yams remains incomplete.

An early exploration of yam phenolic compounds by HPLC revealed that food yams accumulate a rich blend of substances that belong to several chemical classes such as anthocyanins, simple phenolics, flavones and flavonols (Champagne et al., 2011). More recently, a survey of over 500 landraces and hybrids (covering eight species) of staple food yams using high-performance thin-layer chromatography (HPTLC) was able to identify and quantify many phenolic substances (Lebot et al., 2019). These included allantoin, allantoic acid, chlorogenic acids, gallic acids and minor quantities of catechins (both catechin and epicatechin). Among them, chlorogenic acids, gallic acids and catechins are known antioxidant substances (Brand-Williams et al., 1995; Sang et al., 2002). However, despite the large range of authentic standards that was used, one substance present in many species that appeared yellow under white light could not be identified. Interestingly, this was the main phenolic substance of the tubers of some $D$. nummularia landraces which also accumulated the largest content of total phenolics (average of $9.55 \mathrm{mg} / \mathrm{g}$ ).

The objective of this study was therefore to expand our knowledge of the major phenolics/polyphenolics substances of food yams. The major unknown phenolic/polyphenolic substance was purified from a $D$. nummularia landrace where its content was high. Its structure was determined by mass spectrometry and NMR. Its radical scavenging capacity and potential bacterial toxicity were then estimated. A similar process was applied to a minor, and structurally-related, substance. Finally, using the pure substances as standards, their content was estimated by HP-TLC in a panel of 411 yam landraces covering eight staple food species.

\section{Materials and methods}

\subsection{Chemicals}

All chemicals were purchased from Sigma-Aldrich (Darmstadt, Germany) unless otherwise stated. Solvents were of analytical grade and purchased from VWR International (Fontenay-sous-bois, France).

\subsection{Plant material}

All yam accessions (landraces and hybrids) were grown in a common field (Vanuatu Agricultural Research and Technical Centre VARTC - located on Santo Island $80 \mathrm{~m}$ above sea level in Vanuatu $15^{\circ} 23^{\prime} \mathrm{S}$ and $166^{\circ} 51^{\prime} \mathrm{E}$ ) in August 2016 to minimize variations due to environmental factors. For each accession, four seed tubers were planted in a $1 \times 1 \mathrm{~m}$ spacing and stacked together. The experimental setup contained 422 samples deriving from 411 accessions (acc.) of eight Dioscorea species. These included tubers of 273 D. alata acc. (216 acc. from Vanuatu, 57 acc. from India), 15 D. bulbifera acc., 22 D. cayenensisrotundata acc., 2 D. dumetorum acc., 46 D. esculenta acc., 32 D. nummularia acc., $2 D$. pentaphylla acc. and $4 D$. trifida acc. and the aerial bulbils of 26 D. bulbifera acc. (complete list of samples and data in Supplementary data, Table A1). Healthy tubers were harvested at full maturity 10 months after planting.

\subsection{Sample preparation}

Sample preparation was similar to (Lebot et al., 2019). In short, freshly harvested tubers were washed, peeled and cut into $1 \times 1 \mathrm{~cm}$ section French fries. Central fries were swiftly surface-dried with a clean towel to remove excessive mucilage and fully dried in a ventilated oven at $60-70{ }^{\circ} \mathrm{C}$ until constant weight. Dried chips were ground with a Forplex F00 1218 hammer mill (Boulogne, France) to less than $2 \mathrm{~mm}$ particle size powder. Powders were stored away from light at room temperature in Ziplock bags within plastic boxes containing silica gel.

Powders were either used for phenolic compound purification or were extracted with methanol for HP-TLC analyses.

\subsection{Caryatin and $3^{\prime}-O-$-methycaryatin purification}

The high starch and fat content of yam tubers complicates secondary metabolite purification by generating unwanted precipitates and by slowing solubilisation steps. This was particularly the case for $D$. nummularia landraces because of the small nature of their starch grains (Lebot et al., 2017). The following protocol was therefore designed to circumvent these difficulties.

Dried tuber powder of D. nummularia landrace acc. DN2010 ("nasghan iwé" from the island of Vanua Lava, Banks archipelago) was first extracted with hexane $\left(20 \mathrm{~mL} / \mathrm{g}-15 \mathrm{~min}\right.$ incubation at $19^{\circ} \mathrm{C}$ in a bath sonicator). The dried hexane extract yielded a white amorphous powder $(3.1 \mathrm{mg} / \mathrm{g}$ dry tuber powder). The hexane-extracted powder was further extracted with methanol $(20 \mathrm{~mL} / \mathrm{g}$ dry initial tuber powder). Once dried, the methanol extract yielded a red/purple amorphous paste $(13 \mathrm{mg} / \mathrm{g}$ dry initial tuber powder) which was re-dissolved in methanol $\left(0.4 \mathrm{~mL} / \mathrm{g}\right.$ dry initial tuber powder) and left to precipitate at $4{ }^{\circ} \mathrm{C}$ for $12 \mathrm{~h}$ to remove excess polymeric sugars. The final supernatant was mixed with $\mathrm{CHCl}_{3}$ and water to obtain a 28:8:1 chloroform:methanol:water mix. After discarding the upper purple phase and precipitates, the lower yellow phase was dried and dissolved in methanol. Less than $10 \%$ of the two substances of interest was lost during these solvent extractions and cold precipitation steps. The final crude (but stable) methanol extract was injected in an HPLC-DAD (Agilent 1200, Santa Clara, USA) equipped with a RP-18 Nucleodur Sphinx column ( $250 \mathrm{~mm}$ x $10 \mathrm{~mm}, 5 \mu \mathrm{m}$ bead diameter- Macherey Nagel, Hoerdt, France) and eluted with a mix of solvents A $(0,4 \%$ formic acid in water) and $\mathrm{B}$ (acetonitrile). Linear elution gradient conditions were: $0 \min 1 \%$ B, $3 \min 1 \%$ B, $18 \min 15 \%$ B, $36 \min 45 \%$ B, $42 \min 100 \%$ $\mathrm{B}, 46 \min 100 \% \mathrm{~B}, 47 \min 1 \% \mathrm{~B}, 54 \min 1 \% \mathrm{~B}$. The flow rate was $3.5 \mathrm{~mL} / \mathrm{min}$ and the column was at room temperature. Peak detection wavelengths were set at $203 \mathrm{~nm}, 254 \mathrm{~nm}, 280 \mathrm{~nm}, 350 \mathrm{~nm}$, and $450 \mathrm{~nm}$. Peaks IV and VII (Fig. 1) were collected via a fraction collector (G1364C Agilent 1100, Santa Clara, USA). Injections were repeated until sufficient of each substance was obtained for NMR analysis. Purity of 


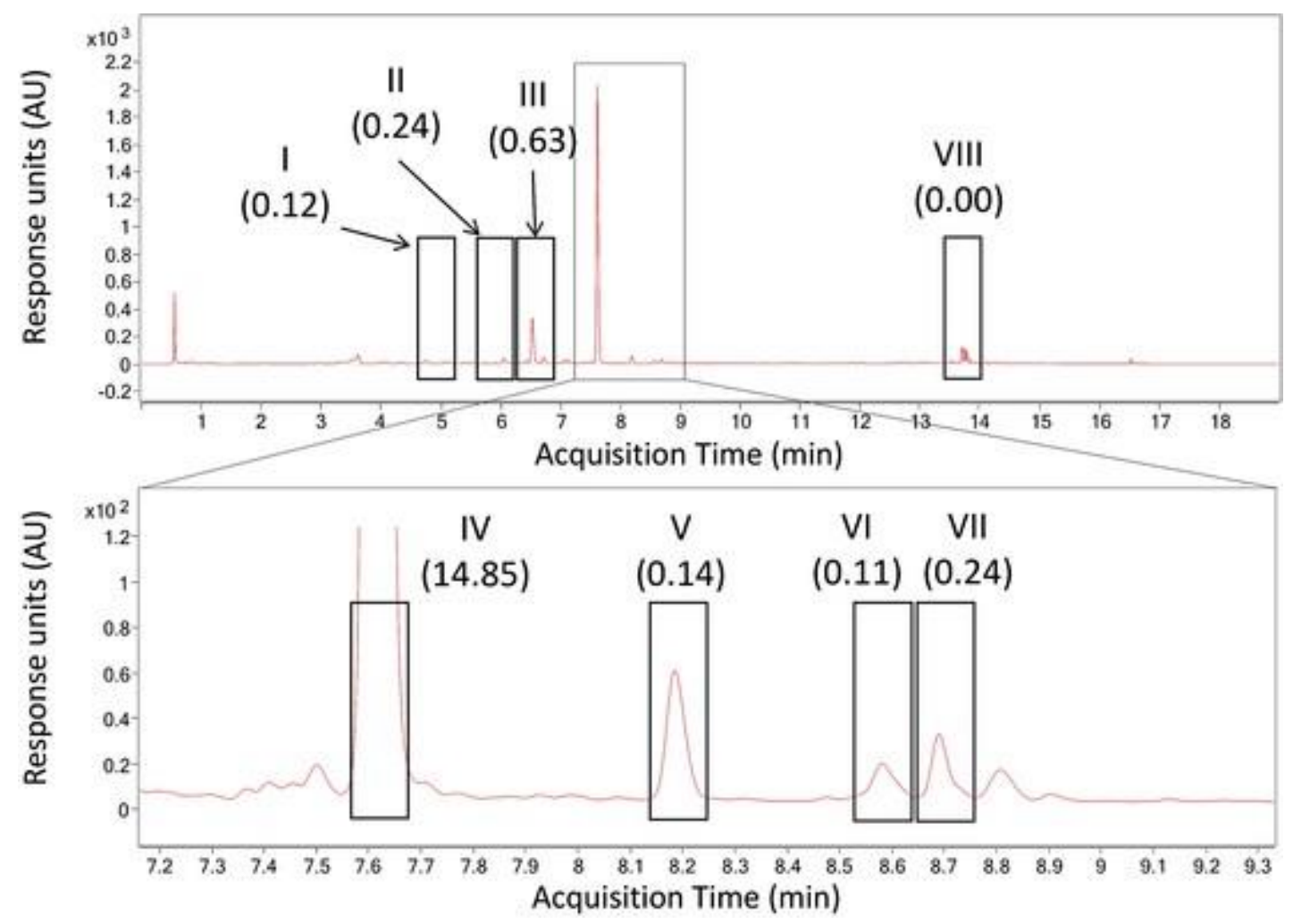

Fig. 1. HPLC-DAD analysis of a crude methanol extract of $D$. nummularia tuber. A typical chromatogram obtained with a detection set at 280 nm is shown. Numbers I-VIII refer to the collected fractions. Numbers in parenthesis represent the TEAC values (x $10^{3} \mathrm{mmol}$ eq. trolox/fraction) of the fractions.

the collected substances was determined by UPLC-DAD-ESI-MS/MS (as in Section 2.5). If insufficiently pure ( $<95 \%$ total ion count - TIC -trace area), fractions IV and VII were re-chromatographed and fractions collection as described above.

\subsection{UPLC-DAD-ESI-MS/MS analysis}

UHPLC-DAD-ESI/QTOF analyses were performed on an Agilent Infinity 1290 system (Agilent Technologies, Santa Clara, USA) coupled to a UV-vis DAD detector and a QTOF 6530 detector (Agilent Technologies, Santa Clara, USA) controlled by MassHunter ${ }^{\circledR}$ software (Agilent Technologies, Santa Clara, USA). Analytic separation was carried out on a Poroshell@ 120 EC-C18 column $(100 \mathrm{~mm} \times 3.0 \mathrm{~mm}, 2.7 \mu \mathrm{m})$ protected by a guard column (Poroshell® 20 EC-C18, $5 \mathrm{~mm}$ x $3.0 \mathrm{~mm}$, $2.7 \mu \mathrm{m}$ ). A gradient of $0.4 \%$ formic acid in water (A) and acetonitrile (B) was applied with the following characteristics: $0 \mathrm{~min}, 1 \% \mathrm{~B}$; $1.5 \mathrm{~min}, 1 \% \mathrm{~B} ; 6 \mathrm{~min}, 10 \% \mathrm{~B} ; 12 \mathrm{~min}, 35 \% \mathrm{~B} ; 14 \mathrm{~min}, 100 \% \mathrm{~B}$; $16 \mathrm{~min}, 100 \% \mathrm{~B}$. The flow rate and column temperature were respectively set at $1.0 \mathrm{~mL} \mathrm{~min}{ }^{-1}$ and $60{ }^{\circ} \mathrm{C}$. A total of $2.0 \mu \mathrm{L}$ of sample extract was injected. The ESI source operating conditions for positive ionization modes (in "Auto MSMS" acquisition mode) were: scan spectra from $\mathrm{m} / \mathrm{z}$ 50-2000, capillary voltage $3.5 \mathrm{kV}$, nozzle voltage $2000 \mathrm{~V}$, fragmentor $110 \mathrm{~V}$, fixed collision-induced dissociation (CID) energy at $20 \mathrm{eV}$. Nitrogen was used as the nebulizing gas with a flow rate of $12 \mathrm{~L}$ $\mathrm{min}^{-1}$ and a temperature of $310^{\circ} \mathrm{C}$ at $40 \mathrm{psi}$.

Spectroscopic and spectrometric characteristics of 1: UV-vis spectrum: 346, 250, 260 (sh), 306 (sh); Pseudomolecular ion $[\mathrm{M}+\mathrm{H}]^{+}$: $331.0803 \mathrm{Da}$; MS/MS fragments (\% relative abundance) : $316.0565 \mathrm{Da}$ (78); 298.0463 Da (77); $270.0516 \mathrm{Da}$ (100).

Spectroscopic and spectrometric characteristics of 2: UV-vis spectrum: 344, 250, 258 (sh), 309 (sh); Pseudomolecular ion $[\mathrm{M}+\mathrm{H}]^{+}$: $345.0945 \mathrm{Da}$; MS/MS fragments (\% relative abundance) : $330.0717 \mathrm{Da}$ (100) ; $312.0624 \mathrm{Da}(68) ; 284.0668 \mathrm{Da}(86)$.

\subsection{NMR analysis}

NMR experiments were run at $25 \pm 0.1^{\circ} \mathrm{C}$ on a Bruker Avance III 500 spectrometer with $\mathrm{BBFO}$ probe for standards, or on a Bruker Avance III $1 \mathrm{GHz}$ spectrometer with a TXI helium cooled cryo probe. NMR experiments were taken from Bruker's Topspin pulse program library. Relaxation delay was $2 \mathrm{~s}$ for all the experiments, a 30 degrees pulse was used for ${ }^{13} \mathrm{C}$ experiments, and 90 degrees for ${ }^{1} \mathrm{H}$. Continuous wave water presaturation was used for COSY and NOESY experiments. All compounds were dissolved in deuterated methanol purchased from Eurisotop. Chemical shifts were referenced to solvent signal.

\subsection{Synthesis of 3'-O-methylcaryatin}

Compound 2 was synthesized according to the scheme shown on Fig. 2. The synthesis of the intermediate 4',7-di-O-benzyl quercetin (compound A) was as reported by Ren et al. (2011). Compounds B and $\mathbf{2}$ were synthesized following procedures reported by Shi et al. (2012) with the following modifications.

Compound B: To a stirring mixture of dibenzylether A $(69 \mathrm{mg}$, $0.143 \mathrm{mmol})$ and $\mathrm{K}_{2} \mathrm{CO}_{3}(138 \mathrm{mg}, 1 \mathrm{mmol}, 7 \mathrm{eq})$ in $6 \mathrm{~mL}$ dry DMF, methyl iodide ( $62 \mu \mathrm{L}, 1 \mathrm{mmol}, 7 \mathrm{eq})$ was added at room temperature. After $12 \mathrm{~h}$, the resulting mixture was diluted with water $(20 \mathrm{~mL})$ and extracted with ethyl acetate $(20 \mathrm{~mL})$. The organic layer was washed with brine, dried over $\mathrm{MgSO}_{4}$, filtered and concentrated. The crude material was purified by column chromatography (30\% AcOEt in petroleum ether) to give $\mathbf{B}$ as an oily product (52 mg, $70 \%$ yield). ${ }^{1} \mathrm{H}$ NMR $\left(\mathrm{CDCl}_{3}, 500 \mathrm{MHz}\right): 3.81$ (s, $\left.3 \mathrm{H}, \mathrm{OCH}_{3}, 11-\mathrm{H}\right), 3.90$ (s, $\left.3 \mathrm{H}, \mathrm{OCH}_{3}, 12-\mathrm{H}\right)$, $3.92\left(\mathrm{~s}, 3 \mathrm{H}, \mathrm{OCH}_{3}, 7^{\prime}-\mathrm{H}\right), 5.09$ (s, 2H, $\left.\mathrm{OCH}_{2} \mathrm{Ph}, 7-\mathrm{H}\right), 5.19$ (s, $2 \mathrm{H}$, $\left.\mathrm{OCH}_{2} \mathrm{Ph}, 4^{\prime}-\mathrm{H}\right), 6.38(\mathrm{~d}, J=2.3 \mathrm{~Hz}, 1 \mathrm{H}, 6-\mathrm{H}), 6.54(\mathrm{~d}, J=2.3 \mathrm{~Hz}, 1 \mathrm{H}$, $8-\mathrm{H}), 6.94\left(\mathrm{~d}, J=8.5 \mathrm{~Hz}, 1 \mathrm{H}, 5^{\prime}-\mathrm{H}\right), 7.28-7.43\left(\mathrm{~m}, 10 \mathrm{H}, \mathrm{OCH}_{2} \mathrm{Ph}\right)$, $7.58\left(\mathrm{dd}, J=8.5 \mathrm{~Hz}, 2.1 \mathrm{~Hz}, 1 \mathrm{H}, 6^{\prime}-\mathrm{H}\right), 7.68\left(\mathrm{~d}, J=2.1 \mathrm{~Hz}, 1 \mathrm{H}, 2^{\prime}-\mathrm{H}\right)$; ${ }^{13} \mathrm{C} \mathrm{NMR}\left(\mathrm{CDCl}_{3}, 125 \mathrm{MHz}\right): 56.2,56.5,60.0,70.6,70.8,93.5,96.4$, $109.5,111.8,113.1,121.5,123.6,127.3,127.7,128.1,128.5,128.7$, 
<smiles>O=c1c(O)c(-c2ccc(O)c(O)c2)oc2cc(O)cc(O)c12</smiles>

Quercetin<smiles>CCCCOc1ccc(-c2oc3cc(OCC(C)C(Cl)(Cl)Cl)cc(O)c3c(=O)c2O)cc1O</smiles>

4:7-di-O-benzyl guercetin

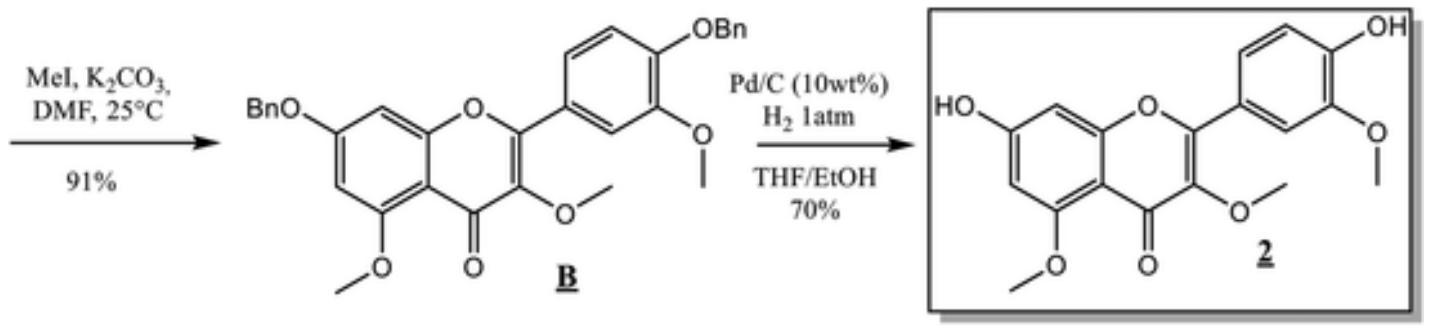

Fig. 2. Synthesis of compound 2 starting from quercetin.

$128.8,135.7,136.6,141.2,149.2,150.0,152.7,158.7,161.0,163.0$, 174.1.

Compound 2: To a solution of $\mathbf{B}(29 \mathrm{mg}, 0.055 \mathrm{mmol})$ dissolved in ethanol $(1.5 \mathrm{~mL})$ and THF $(1.5 \mathrm{~mL}), 5 \% \mathrm{Pd} / \mathrm{C}(10 \mathrm{mg})$ was added under vigorous stirring. The reaction vessel was evacuated and the atmosphere replaced by hydrogen. After $12 \mathrm{~h}$, the reaction mixture was filtered through celite, concentrated and purified by flash chromatography (50\% AcOEt in petroleum ether) to yield 2 (9 mg, $50 \%) .{ }^{1} \mathrm{H}$ NMR $\left(\mathrm{CD}_{3} \mathrm{OD}, 500 \mathrm{MHz}\right): 3.77$ (s, 3H, $\left.\mathrm{OCH}_{3}, 11-\mathrm{H}\right), 3.90$ (s, $3 \mathrm{H}, \mathrm{OCH}_{3}, 12-$ H), $3.94\left(\mathrm{~s}, 3 \mathrm{H}, \mathrm{OCH}_{3}, 7^{\prime}-\mathrm{H}\right), 6.40(\mathrm{~d}, J=2.1 \mathrm{~Hz}, 1 \mathrm{H}, 6-\mathrm{H}), 6.51$ (d, $J=2.1 \mathrm{~Hz}, 1 \mathrm{H}, 8-\mathrm{H}), 6.94\left(\mathrm{~d}, J=8.5 \mathrm{~Hz}, 1 \mathrm{H}, 5^{\prime}-\mathrm{H}\right), 7.61$ (dd, $\left.J=8.5 \mathrm{~Hz}, 2.1 \mathrm{~Hz}, 1 \mathrm{H}, 6^{\prime}-\mathrm{H}\right), 7.71\left(\mathrm{~d}, J=2.1 \mathrm{~Hz}, 1 \mathrm{H}, 2{ }^{\prime}-\mathrm{H}\right) ;{ }^{13} \mathrm{C} \mathrm{NMR}$ $\left(\mathrm{CD}_{3} \mathrm{OD}, 125 \mathrm{MHz}\right): 56.4,56.5,60.3,96.1,97.1,108.7,112.8,116.4$, $123.1,123.3,141.5,148.9,150.7,155.3,160.2,162.5,164.8,176.1$

$\mathrm{C}$ numbering followed accepted rules for flavonoids and is recalled on Fig. 3.

\subsection{Antioxidant assay}

Substances 1, 2 and quercetin were dried and dissolved in methanol:water (80:20) at a final concentration of $0.1 \mathrm{mg} / \mathrm{mL}$. They were then cascade-diluted by a factor of 3 in water. Diluted fractions $(100 \mu \mathrm{L})$ were mixed with $1 \mathrm{~mL}$ of $12 \mathrm{~h}$ old 2,2'-azino-bis(3éthylbenzothiazoline-6-sulphonic) acid (ABTS) solution (19.2 mg ABTS dissolved in $5 \mathrm{~mL}$ of water, mixed with $3.312 \mathrm{mg}$ potassium persulfate and diluted to $400 \mathrm{~mL}$ with ethanol). After $30 \mathrm{~min}$ of incubation at room temperature, the absorbance was read at $734 \mathrm{~nm}$ and the antioxi- dant activity estimated against a standard curve of trolox. The remaining fraction of oxidized ABTS (expressed as \% of initially oxidized $\mathrm{ABTS}=\mathrm{OD}_{734}$ assay tube $/ \mathrm{OD}_{734}$ blank tube containing $1 \mathrm{~mL}$ of oxidized ABTS and $100 \mu \mathrm{L}$ of water) was then calculated for each assay tube and plotted against the quantities of substances 1, 2, quercetin or trolox (expressed in mmol) or volume of collected fractions I-VIII (expressed in 1). TEAC indices were finally calculated for each purified substance as:

$\mathrm{TEAC}=\left(\mathrm{IC}_{50}\right.$ Trolox $) /\left(\mathrm{IC}_{50}\right.$ substance $)$

$\mathrm{IC}_{50}$ : quantity of pure substance (mmol) or collected fraction (1) yielding $50 \%$ reduction of the initially oxidized ABTS.

The measurements were made in triplicate and the results averaged.

\subsection{Anti-bacterial assay}

Aliquots of $-80{ }^{\circ} \mathrm{C}$ glycerol stocks of Escherichia coli and Bacillus megaterium were plated on solid nutrient agar. Single colonies were transferred to $10 \mathrm{~mL}$ of liquid nutrient agar and grown at $28{ }^{\circ} \mathrm{C}$ under gentle stirring $(160 \mathrm{rpm})$ for $18 \mathrm{~h}$. Proportionalities between the number of colony forming units (CFU) and $\mathrm{OD}_{600}$ were respectively determined to be $1 \mathrm{OD}_{600}=2.610^{10} \mathrm{CFU}$ for $E$. coli and $1 \mathrm{OD}_{600}=1.210^{7}$ $\mathrm{CFU}$ for B. megaterium.

Dried substances $\mathbf{1}, \mathbf{2}$ or tetracyclin $(320 \mu \mathrm{g})$ were dissolved in $80 \mu \mathrm{L}$ dimethyl sulfoxide (DMSO) and mixed with $720 \mu \mathrm{L}$ sterile Mueller-Hinton (MH) liquid medium. They were then cascade-diluted by a factor of 2 directly in the wells of a 96 microwell plate (final vol-

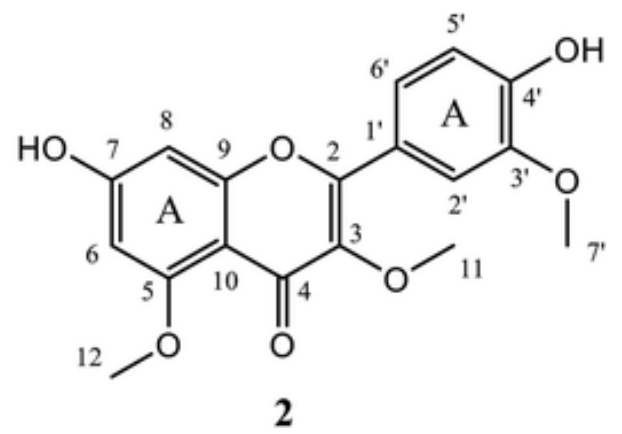

Fig. 3. Structure of the two substances purified in this study. 1: caryatin; 2: $3^{\prime}-\mathrm{O}-$-methylcaryatin. C-numbering and aromatic rings names are indicated on the structure of $\mathbf{2}$. 
ume of $50 \mu \mathrm{L})$. Sterile MH medium $(100 \mu \mathrm{L})$ and $18 \mathrm{~h}$ old bacterial culture $(50 \mu \mathrm{L})$ were then added. In parallel, a positive control (PCT) well was constructed that contained MH medium instead of the purified substances. Two types of negative control wells were also constructed. One only contained MH medium (NCT1 - to check for microbial contaminants) and one contained $\mathrm{MH}$ medium instead of the bacterial cultures (NCT2 - to subtract the absorbance of the diluted substances from the corresponding test samples). Each well was constructed in duplicate and average values were calculated. Plates were incubated at $28^{\circ} \mathrm{C}$ for $24 \mathrm{~h}$ before being read at $\mathrm{OD}_{600}$. The anti-bacterial activity $\left(\mathrm{BT}_{\text {test }}\right)$ was estimated with the following formula:

$\mathrm{BT}_{\text {test }}=\left(\left(\mathrm{OD}_{600}\right.\right.$ test $\left.-\mathrm{OD}_{600}-\mathrm{NCT} 2\right) * 100 /\left(\mathrm{OD}_{600}+\mathrm{PCT}-\mathrm{OD}_{600}-\right.$ NCT1))-100

and plotted against the substance concentration. Concentrations leading to $50 \%$ inhibition of bacterial growth $\left(\mathrm{IC}_{50}\right)$ were then determined.

\subsection{HP-TLC analyses}

Methanol extraction (10 g powder and $20 \mathrm{~mL}$ of methanol) was carried in a bath sonicator (Lab Companion UC-02, Cole Parmer, Vernon Hills, IL, USA) for $10 \mathrm{~min}$. Part of the supernatant was transferred to a $1 \mathrm{~mL}$ amber sample vial (Chromacol ${ }^{\mathrm{TM}}$, Thermo Fisher $^{\mathrm{TM}}$, USA) and stored at $4{ }^{\circ} \mathrm{C}$ in the dark until analysis.

Yam tuber methanolic extracts $(5.0 \mu \mathrm{L})$ were loaded on HP-TLC silica gel 60 F254 plates (Merk, Darmstadt, Germany, $20 \times 10 \mathrm{~cm}$ glass plates, Ref 1.05642.0001) as straight $8.0 \mathrm{~mm}$ wide bands using an automatic sample loading unit (Camag, Muttenz, Switzerland). In parallel, increasing concentrations of purified caryatin and synthesized 3 '-0methylcaryatin were loaded to cover a concentration range of 1.0, 2.0, $4.0,6.0,8.0$ and $10.0 \mu \mathrm{g}$. Plates were run for a total distance of $8 \mathrm{~cm}$ with $10 \mathrm{~mL}$ of toluene:ethyl acetate:formic acid (4:6:1 v/v) as mobile phase. Plates were air-dried and stained with NP reagent before being scanned at $366 \mathrm{~nm}$. All machines were controlled online with winCATS $^{\text {TM }}$ software (Camag, Muttenz, Switzerland).

Caryatin and 3'-O-methylcaryatin were identified in the yam extracts on the basis of their color when visualized at $366 \mathrm{~nm}$, their UV-vis absorption spectrum, their Rf values and a comparison with

pure standards. Their quantity in the extracts was estimated from their peak areas (scan at $366 \mathrm{~nm}$ ) that were plotted against standard curves constructed with the peak areas of the pure standards. Peak separation was good for the two substances in all extracts at the scanning wavelength. The repeatability of the measurements was determined to be greater than $95 \%$ for both substances during two parallel analyses of a yam sample. The standard curves that were constructed with the two substances had a Pearson correlation coefficient of 0.99 .

\section{Results and discussion}

\subsection{Phytochemicals purification}

HPLC-DAD analysis of crude D. nummularia methanol extracts typically yielded a single major UV absorbing peak flanked by minor peaks (Fig. 1). This major peak also made most of the total ion count (TIC) trace area from UPLC-MS/MS analysis. This agrees with an HP-TLC analysis of yam phytochemicals where $D$. nummularia methanol extracts were characterized by a single major yellow band and several minor bands (Lebot et al., 2019). This unidentified reported yellow substance had a similar UV-vis absorption spectrum as the major peak seen on Fig. 1.

The eight most UV-absorbing peaks of the crude D. nummularia methanol extract chromatogram were collected separately after their LC separation (fractions I-VIII on Fig. 1). Fraction IV clearly contained most of the antioxidant activity of the extract since it made $91 \%$ of the sum of the TEAC of the tested fractions (which was roughly equal to the one of the injected sample). Focus was therefore placed on fraction IV. Attention was also placed on fraction VII because it was also a significant contributor to the overall antioxidant activity and because it was a single major substance (more than $85 \%$ of the total TIC trace area from UPLC-MS/MS analysis) unlike fractions II and III. After a second LC cleanup, the two purified substances, $\mathbf{1}$ and $\mathbf{2}$ (Fig. 3) respectively originating from fractions IV and VII, represented more than $95 \%$ of the total TIC trace areas from UPLC-MS/MS analysis.

\subsection{Structure determination}

Compounds $\mathbf{1}$ and $\mathbf{2}$ shared a similar UV-vis spectrum that was characterized by two absorption maxima (250 \& $346 \mathrm{~nm}$ and 250 \& $344 \mathrm{~nm}$ respectively) flanked by a shoulder $(260 \& 306 \mathrm{~nm}$ and 258 \& $309 \mathrm{~nm}$ respectively). Such a UV-vis spectrum is typical of flavonols, a class of flavonoids (Markham and Mabry, 1975). The fact that absorption maxima were in the low range for flavonols suggested that $\mathbf{1}$ and $\mathbf{2}$ could be methoxylated at positions 3, 5 and/or 4' (Markham and Mabry, 1975). Their respective pseudomolecular ions at $\mathrm{m} / \mathrm{z}$ 331.0803 Da and 345.0945 Da for $[\mathrm{M}+\mathrm{H}]^{+}$under HRMS suggested molecular formulas of $\mathrm{C}_{17} \mathrm{H}_{14} \mathrm{O}_{7}$ and $\mathrm{C}_{18} \mathrm{H}_{16} \mathrm{O}_{7}$ respectively. These correspond to a trihydroxydimethoxy flavonol and a dihydroxyltrimethoxy flavonol respectively. Both compounds had a similar MS/MS fragmentation profile with ions of $\mathrm{m} / \mathrm{z} 316.0565 \mathrm{Da}(-15, \cdot \mathrm{CH} 3), 298.0463 \mathrm{Da}$ $\left(-33, \cdot \mathrm{CH}_{3}+\mathrm{H}_{2} \mathrm{O}\right), 270.0516 \mathrm{Da}\left(-61, \cdot \mathrm{CH}_{3}+\mathrm{H}_{2} \mathrm{O}+\mathrm{CO}\right)$ for $\mathbf{1}$ and $330.0717 \mathrm{Da}\left(-15, \cdot \mathrm{CH}_{3}\right), 312.0624 \mathrm{Da}\left(-33, \cdot \mathrm{CH}_{3}+\mathrm{H}_{2} \mathrm{O}\right)$, $284.0668 \mathrm{Da}\left(-61, \cdot \mathrm{CH}_{3}+\mathrm{H}_{2} \mathrm{O}+\mathrm{CO}\right)$ for 2 . This suggests that they share some basic structural characteristics that differ by a methylene group or bridge and that they both contain at least one methoxy group. To confirm the flavonoid core structure and determine the position of the hydroxyl and methoxy groups, NMR analyses were conducted (full NMR data are present on Supplementary data, Fig. A1).

Compound 1. ${ }^{1} \mathrm{H}$ and COSY NMR spectra of compound 1 showed two aromatic spin systems: one with 2 protons attributed to ring $\mathrm{A}$ (6.52 and $6.42 \mathrm{ppm}, \mathrm{d}, J=1.5 \mathrm{~Hz}, 1 \mathrm{H}, \mathrm{H} 6$ and $\mathrm{H} 8$ ) and the other one with 3 protons corresponding to ring B : H-2' ( 7.63, d $J=2 \mathrm{~Hz}, 1 \mathrm{H}) \mathrm{H}-$ $6^{\prime}(7.53 \mathrm{pm}, \mathrm{dd}, J=2$ and $8.5 \mathrm{~Hz}, 1 \mathrm{H})$ and $\mathrm{H}-5^{\prime}$ (6.9 ppm, d $J=8.5 \mathrm{~Hz}, 1 \mathrm{H})$. Two methoxy groups were visible on the $\mathrm{H}$ spectrum. One of them $(3.9 \mathrm{ppm}, \mathrm{s}, 3 \mathrm{H})$ gave a long range correlation with the proton at $6.42 \mathrm{ppm}$, which is attributed to H-6. The other methoxy showed a NOE interaction with protons $2^{\prime}$ and $6^{\prime}$ which confirmed its position on carbon 3 . HSQC analysis assigned the primary and tertiary carbons (C-6' : $122.1 \mathrm{ppm}$; C-5' : 116.5 ppm; C-2' : 116.3 ; C-6 : $97.3 \mathrm{ppm}$; $\mathrm{C}-8$ : $96.2 \mathrm{ppm}: \mathrm{O}_{-} \mathrm{CH}_{3}$ (3) : $60.0 \mathrm{ppm} ; \mathrm{O}-\mathrm{CH}_{3}(5)$ : $56.6 \mathrm{ppm})$. C-4 was identified by its chemical shift (176.2 ppm). HMBC analysis assigned $\mathrm{C}-1^{\prime}$ and $\mathrm{C}-3$ ' ( ${ }^{3} \mathrm{~J}$ coupling with $\mathrm{H}-5^{\prime}$ ': respectively 123.1 and $146.3 \mathrm{ppm}), \mathrm{C}-10$ ( ${ }^{3} \mathrm{~J}$ coupling with $\mathrm{H}-6$ and $\mathrm{H}-8$, 108.5 ppm), C-7 ( ${ }^{2} \mathbf{J}$ with H-6 and H-8, 165 ppm, ), C-9 ( ${ }^{2} \mathbf{J}$ with H-8, 160.2).

$\mathrm{C} 2$ and $\mathrm{C} 4$ showed the same correlations, ( $3 \mathrm{~J}$ coupling with $\mathrm{H}-2^{\prime}$, and $\mathbf{H}-6^{\prime},{ }^{4} \mathbf{J}$ or ${ }^{2} \mathbf{J}$ with $\mathrm{H}-5^{\prime}$ ) and were assigned to the peaks at $155.5 \mathrm{ppm}$ and $149.4 \mathrm{ppm}$ respectively, with the help of MNova simulation software.

It was therefore concluded that $\mathbf{1}$ is caryatin (Fig. 3). Caryatin has been previously described in two unrelated woody species, the pecan tree, Carya illinoinensis (Abdallah et al., 2011; Xu et al., 2020), and Rhododendron delavayi (Song et al., 2009) and in the medicinal yam of Nigeria, D. hirtiflora (Adeniran et al., 2020) and China, D. bulbifera (Gao et al., 2002). This study makes nevertheless, the first description of caryatin in the flesh of a food yam tuber.

Compound 2. Three methoxy groups were visible on the proton NMR spectrum of compound 2, as suspected by Mass and UV spectroscopies. ${ }^{1} \mathrm{H}$ and COSY NMR spectra showed a 3 spins systems in the aromatic regions corresponding to the $2^{\prime}, 5^{\prime}, 6^{\prime}$ protons of ring $\mathrm{B}$. The coupling constants confirmed the assignment to $2^{\prime}$ (7.71 ppm, d, 
$J=2.1 \mathrm{~Hz}, 1 \mathrm{H}) 5^{\prime}(6.94 \mathrm{ppm}, \mathrm{d}, J=8.5 \mathrm{~Hz}, 1 \mathrm{H})$ and $6^{\prime}(7.61 \mathrm{ppm}$, $\mathrm{dd}, J=8.5 \mathrm{~Hz}, 2.1 \mathrm{~Hz}, 1 \mathrm{H})$. A second 2 spins system corresponded to the $\mathrm{H}-8$ and $\mathrm{H}-6$ protons of the second aromatic ring. Long range COSY weaker signals, confirmed by NOESY between $\mathrm{H}-2$ ' and the methoxy at $3.94 \mathrm{ppm}$, and between H-6 and the methoxy at $3.90 \mathrm{ppm}$ assigned them to $\mathrm{H}^{-7}$ ' and $\mathrm{H}-12$ respectively, and removed ambiguity between the protons $\mathrm{H}-6(6.40 \mathrm{ppm}, \mathrm{d}, J=2.1 \mathrm{~Hz}, 1 \mathrm{H})$ and $\mathrm{H}-8(6.51 \mathrm{ppm} \mathrm{d}$, $J=2.1 \mathrm{~Hz}, 1 \mathrm{H})$. A weak NOE interaction was observed between $\mathrm{H}-11$ methoxy $\left(3.77 \mathrm{~s}, 3 \mathrm{H}, \mathrm{OCH}_{3}\right)$ and $\mathrm{H}-2^{\prime}$ and $\mathrm{H}-6$ ' protons.

HSQC analysis assigned the corresponding protonated carbons $(\mathrm{C}$ 12: 56.4 ppm; C-7'; 56.5 ppm, C-11 ; 60.3 ppm; C-8 ; 96.1 ppm, C-6 ; 97.1 ppm; C-2': 112.8 ppm; C-5': 116.4 ppm, C-6'; 123.3 ppm). C-4 was identified by its chemical shift (176.1 ppm). On the HMBC spectrum, the ${ }^{3} \mathbf{J}$ correlations between methoxy groups and carbons at 141.5, 148.9 and 162.5 ppm confirmed their assignment C-3, C-3' and C-5 respectively. HMBC analysis assigned C-1' ( ${ }^{3} \mathrm{~J}$ coupling with $\mathrm{H}-$ 5'123.1 ppm), C-4' ( ${ }^{2} \mathrm{~J}$ coupling with H-5', $\left.150.7 \mathrm{ppm}\right), \mathrm{C}-2$ ( ${ }^{3} \mathrm{~J}$ coupling with H-2' and H-6', 155.3 ppm) C-9 ( ${ }^{2} \mathbf{J}$ coupling with C-8, 160.2). The other HMBC correlations were consistent with the proposed structure ( 3 '-O-methylcaryatin). The 2 remaining carbons (C-10, $108.7 \mathrm{ppm}$ and $C 7164.8 \mathrm{ppm}$ ) were differentiated by their chemical shift values, through simulations with MNOVA and ACDLabs softwares.

The NMR analysis of $\mathbf{2}$ was consistent with the proposed structure, but did not confirm it, hence an authentic of 3'-O-methylcaryatin was de novo synthesized (Fig. 2). The retention times and mass fragmentation profiles of the synthetic sample matched those of the purified substances through UPLC-DAD-MS/M analysis. Moreover, ${ }^{1} \mathrm{H}$ and ${ }^{13} \mathrm{C}$ chemical shifts of the purified $\mathbf{2}$ matched with an excellent precision (< $0.1 \mathrm{ppm}$ ) those of the synthetized authentic compound (Supplementary data, Fig. A1). The minor peaks at 0.7-1.5 ppm in the proton spectrum, and around $160 \mathrm{ppm}$ in the ${ }^{13} \mathrm{C}$ spectrum were therefore attributed to impurities accompanying purified $\mathbf{2}$. It is therefore concluded that $\mathbf{2}$ is 3'-O-methylcaryatin (Fig. 3).

3'-O-methylcaryatin has only been previously described in C. illinoinensis (Abdallah et al., 2011; Xu et al., 2020) and is described here for the first time in Dioscorea.

\subsection{Biological activities}

$\mathbf{1}$ and $\mathbf{2}$ are flavonols, a class of phenolic compounds with known antioxidant activity (Shahidi and Ambigaipalan, 2015). Measurements of their ABTS radical scavenging activity revealed that $\mathbf{1}$ had a trolox equivalent antioxidant capacity (TEAC) index of 0.74 and 2 of 0.43 . These indices were respectively 4 and 6.8 times lower than for quercetin, a common flavonol with known antioxidant activity (Table 1).

The mechanism of the antioxidant activities of plant phenolic substances including flavonols such as $\mathbf{1}$ and $\mathbf{2}$ has been extensively studied (Dueñas et al., 2010; Letan, 1966; Shahidi and Ambigaipalan, 2015). Structure-function analyses of flavonoid antioxidant activity have concluded that $3^{\prime}, 4^{\prime}$ - $\mathrm{diOH}$ and to a lesser extent 5-OH, 3-OH and a conjugation of the A and B rings via a 4-keto and $\mathrm{C} 2-\mathrm{C} 3$ double bond are the positive contributors of the activity (Shahidi and Ambigaipalan, 2015). As such, quercetin has the highest activity of all flavonoids (Shahidi and Ambigaipalan, 2015) with its methyl ethers being less active. $\mathbf{1}$ and $\mathbf{2}$ were respectively found to only retain $2 \%$ and $1 \%$ of the quercetin de-

Table 1

Biological activities of caryatin (1), 3'-O-methylcaryatin (2) and quercetin.

\begin{tabular}{llll}
\hline Substances & TEAC $^{\mathrm{a}}$ & $\mathrm{IC}_{50}$ E. coli & $\mathrm{IC}_{50}$ B. megaterium \\
\hline 1 & & & \\
2 & $0.74+/-0.01$ & $>50 \mu \mathrm{g} / \mathrm{mL}$ & $>50 \mu \mathrm{g} / \mathrm{mL}$ \\
quercetin & $0.43+/-002$ & $>50 \mu \mathrm{g} / \mathrm{mL}$ & $>50 \mu \mathrm{g} / \mathrm{mL}$ \\
\hline
\end{tabular}

a Trolox equivalent antioxidant capacity expressed as mean $+/-$ standard deviation $(\mathrm{n}=3)$. rived lipid peroxidation protection activity (Letan, 1966). Using the ABTS radical scavenging assay, minor losses of activity were induced by O-methyl groups since 3'-O-methylquercetin retained a third of the TEAC index of quercetin (Dueñas et al., 2010). In agreement with this later observation, 1 and 2 TEAC indices were found to be $25 \%$ and 14 $\%$ of the one measured for quercetin (Table 1 ).

Nevertheless, the impact of flavonols on animal health cannot be predicted from their sole in vitro antioxidant capacity. Methylation of quercetin has indeed been shown to improve intestinal absorption and confer resistance to hepatic metabolism (Wen and Walle, 2006). These two features increase the in vivo efficacy of flavonols on non-intestinal targets. Upon ingestion, 2 was actually found to be a more effective antioxidant (in terms of internal reduced glutathione and malondialdehyde levels) than 1 (Abdallah et al., 2011). Flavonols also provide additional benefits to animal health with different structure-activity relationships than their antioxidant capacity. For example, kaempferol-3,5dimethyl ether displayed an at least 5 times greater anti-tumoral activity than $\mathbf{1}$ and myricetin (Gao et al., 2002). $\mathbf{2}$ had a greater hypoglycemic effect than $\mathbf{1}$ (Abdallah et al., 2011). Additional animal studies are still needed to estimate the respective health contribution of the different flavonols present in food preparations.

Both 1 and $\mathbf{2}$ exhibited no measurable toxicity towards a Gram positive and a Gram negative bacteria (Table 1). Concentrations above $8 \mu \mathrm{g} / \mathrm{mL}$ even improved bacterial growth and a $20 \%$ increases in the cellular densities was observed for both bacteria at $50 \mu \mathrm{g} / \mathrm{mL}$ of $\mathbf{1}$ and $\mathbf{2}$, probably because they served as carbon food source.

\subsection{Caryatin and 3'-O-methylcaryatin distribution inyams}

HP-TLC is a robust, accurate and cost-efficient technology for the high-throughput quantitation of phytochemicals (Agatonovic-Kustrin et al., 2017). It has proved to be effective on starchy produce such as yam tubers (Lebot et al., 2019)).

Using HP-TLC and standard curves constructed with pure substances, the contents of $\mathbf{1}$ and $\mathbf{2}$ were estimated in the mature tubers of a large panel of 411 landraces covering eight yam species (Supplementary data, Table A1; Fig. 4). Landraces of D. nummularia contained the highest contents of $\mathbf{1}$ and $\mathbf{2}$ with respective mean values of 310 and $91 \mu \mathrm{g} / \mathrm{g}$ of DW. Highest values were 1030 and $457 \mu \mathrm{g} / \mathrm{g}$ DW respectively. Analyzed landraces of $D$. bulbifera also contained high contents of $\mathbf{1}$ and $\mathbf{2}$, although both substances were of more similar abundance in $D$. bulbifera than in D. nummularia. Aerial bulbils contained roughly twice the quantities of $\mathbf{1}$ and $\mathbf{2}$ than tubers with respective mean contents of 216 and $174 \mu \mathrm{g} / \mathrm{g} \mathrm{DW}$. This agrees with the reported pharmacological use of this species (Guan et al., 2017; Kundu et al., 2020). With contents of 1 and 2 reaching up to 179 and $241 \mu \mathrm{g} / \mathrm{g}$ DW respectively, some landraces of $D$. alata also contained very important quantities of these substances. Nevertheless, most landraces accumulated no detectable amount of these substances. Within the analyzed panel of $D$. alata accessions, Indian landraces contained on average higher contents than those from Vanuatu with mean content values that were 4.1 and 13.2 times higher for $\mathbf{1}$ and $\mathbf{2}$ respectively. Only a few landraces of D. esculenta contained low amounts of $\mathbf{1}$ and $\mathbf{2}$ and $\mathbf{1}$ was only detectable in some landraces of $D$. pentaphylla. All analyzed landraces of D. cayenensis-rotundata, $D$. dumetorum and $D$. trifida contained no detectable amount of $\mathbf{1}$ and $\mathbf{2}$.

One puzzling result of this study is the very disparate levels of accumulation of $\mathbf{1}$ and $\mathbf{2}$ which ranged from $0.1 \%$ of dry weight content to nil in the analyzed sampling. Wild $D$. nummularia originates from The Philippines, Indonesia and Melanesia. It was domesticated on multiple, independent occasions in Melanesia during prehistoric times and quickly dispatched to neighboring Micronesia and Polynesia (Chaïr et al., 2016). This, and other Asian species such as the related to D. alata (Couto et al., 2018) and D. bulbifera accumulated high concentrations of $\mathbf{1}$ and $\mathbf{2}$. However, accumulation of $\mathbf{1}$ and $\mathbf{2}$ was not important in all 


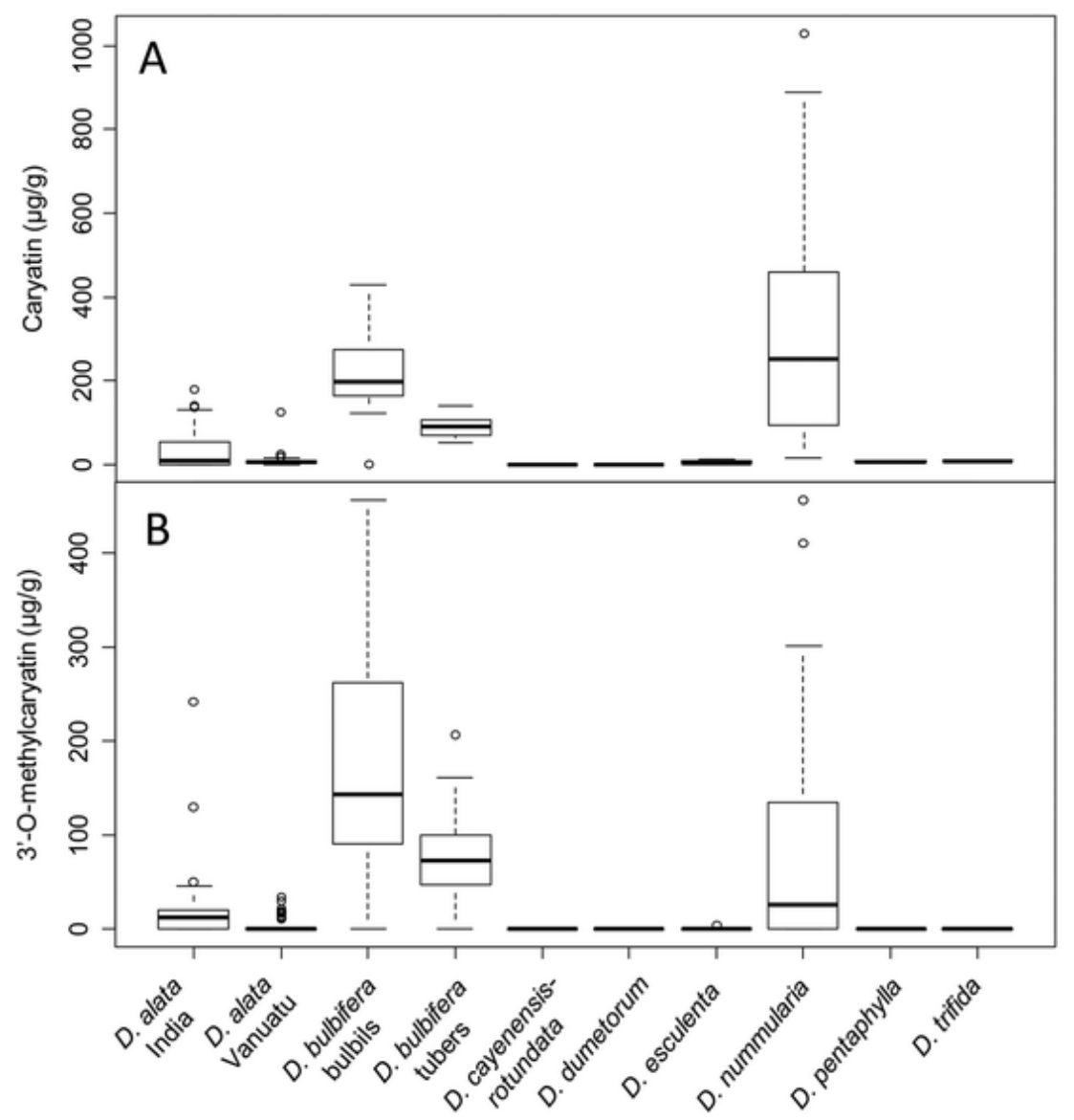

Fig. 4. Box plot analysis of caryatin (A) and $3^{\prime}-\mathrm{O}-$ methylcaryatin (B) contents in 411 accessions of yam spanning eight species.

Asian yams and may occur in non-Asian species such as the African yam, D. hirtiflora, also known to accumulate $\mathbf{1}$ (Adeniran et al., 2020). This study also found that intraspecific variations of $\mathbf{1}$ and $\mathbf{2}$ concentrations are as important as interspecific differences and may reach 2-3 orders of magnitude. This may be the result of a process of selection since all analyzed landraces are actively cultivated to serve a diversity of uses including daily food and ceremonial occasions. At its higher accumulation levels, $\mathbf{1}$ will provide a yellow tinge to the tuber flesh that can be used as a selection character. Inversely, the quest for white ceremonial varieties may explain the existence of landraces with barely undetectable amounts of $\mathbf{1}$.

One major contribution of this work is that it reveals that $\mathbf{1}$ and $\mathbf{2}$ are significant contributors of the antioxidant activity of the tubers of many landraces of $D$. bulbifera, D. alata and D. nummularia. In the case of the D. nummularia landrace that was used for the purification of $\mathbf{1}$ and $\mathbf{2}$, these substances were the main phenolics/polyphenolics (this study and Lebot et al., 2018) and logically the main contributors of its antioxidant activity. However, many food yams may accumulate additional phenolic substances with antioxidant activity such as chlorogenic acids, gallic acids and catechins (Lebot et al., 2018). These will be additional contributors of the tubers antioxidant power. Based on the results of this study and those of Lebot et al. (2018), the respective accumulation of all these phenolic substances will be very dependent on species and, to a similar extent, to the landrace that is selected. Although it has not yet been explored, growing conditions may also have an impact on the accumulation levels of individual phenolics.

This study raises interest in the marginally-cultivated South Pacific yam $D$. nummularia. Its tubers contained the highest quantities of $\mathbf{1}$ and $\mathbf{2}$ of the analyzed yam landrace panel. This species is the main staple crop of large parts of Papua New Guinea and Vanuatu (Walter and Lebot, 2003). It exhibits several superior agronomic characteristics to other cultivated staple yam species such as high yields (up to $40 \mathrm{t} / \mathrm{ha}$ ), resistance to anthracnose (Colletotrichum gloeosporioides), development on many soils (incl. acidic) and production of tubers that are easier to harvest (less buried, no attachment point) and contain a high dry matter (31-36 \%) and starch (78-90\%), contents that most likely explain their high food appreciation and long shelf life (Lebot et al., 2017).

\section{Conclusion}

This study confirms that several widely cultivated species of food yams contain caryatin (1) and 3'-O-methylcaryatin (2), two antioxidant substances with known benefits for human health. They were most abundant in D. bulbifera, that has a long record of food and medicinal use, D. alata and D. nummularia where caryatin alone explained over 90 $\%$ of the total antioxidant activity of a landrace tuber methanol extract. Measured intra- and interspecific variations in concentration were equally large. This suggests that there is ample room for biofortification of many yams with these substances via interspecific hybridization and intraspecific landrace improvement.

\section{Author contributions}

S.C., V.L. and L.L. conceived and designed the experiments. B.F., A.B., F.F., V.L. and L.L. performed the experiments. B.F., A.B., F.F., S.C., V.L. and L.L. analyzed the data. L.L. wrote the manuscript reviewed by all authors. 


\section{Funding}

This research was funded by the French national agency for research 'Agence Nationale pour la Recherche' [Grant number ANR-2010-STRA007].

\section{Declaration of Competing Interest}

The authors report no declarations of interest.

\section{Acknowledgements}

Solène Ravel (Lycée Simone Weil, Le Puy en Velay, France) and Timoté Gard (IUT, University Lyon 1, France) are thanked for Their technical support. Authors thank the IR-RMN-THC Fr3050 CNRS for providing access to the $1 \mathrm{GHz}$ instrument in « Centre de RMN à très Hauts Champs, Lyon". Pr David Leach is thanked for proof-reading the manuscript.

\section{Appendix A. Supplementary data}

Supplementary material related to this article can be found, in the online version, at doi:https://doi.org/10.1016/j.jfca.2021.104010.

\section{References}

Abdallah, H.M., Salama, M.M., Abd-Elrahman, E.H., El-Maraghy, S.A., 2011. Antidiabetic activity of phenolic compounds from Pecan bark in streptozotocin-induced diabetic rats. Phytochem. Lett. 4 (3), 337-341. https://doi.org/10.1016/j.phytol.2011.07.004.

Adeniran, A.A., Sonibare, M.A., Ajayi, O.S., Rajacharya, G.H., Kumar, S., 2020. Antioxidant activity of column fractions and caryatin isolated from the ethyl acetate extract of Dioscorea hirtiflora tuber. Trop. J. Nat. Prod. Res. 4(7), 276-281. https://doi. org/10.26538/tjnpr/v4i7.4.

Agatonovic-Kustrin, S., Milojković-Opsenica, D., Morton, D.W., Ristivojević, P., 2017. Chemometric characterization of wines according to their HPTLC fingerprints. Eur. Food Res. Technol. 243 (4), 659-667. https://doi.org/10.1007/s00217-016-2779-9.

Asiedu, R., Sartie, A., 2010. Crops that feed the world 1. Yams. Food Secur. 2 (4), 305315. https://doi.org/10.1007/s12571-010-0085-0.

Aumsuwan, P., Khan, S., Khan, I.A., Ali, Z., Avula, B., Walker, L.A., Shariat-Madar, Z., Helferich, W.G., Katzenellenbogen, B.S., Dasmahapatra, A.K., 2016. The anticancer potential of steroidal saponin, dioscin, isolated from wild yam (Dioscorea villosa) root extract in invasive human breast cancer cell line MDA-MB-231 in vitro. Arch. Biochem. Biophys. 591, 98-110. https://doi.org/10.1016/j.abb.2015.12.001.

Brand-Williams, W., Cuvelier, M.E., Berset, C.L.W.T., 1995. Use of a free radical method to evaluate antioxidant activity. LWT-Food Sci. Technol. 28 (1), 25-30. https://doi.org/10. 1016/s0023-6438(95)80008-5.

Cayen, M.N., Dvornik, D., 1979. Effect of diosgenin on lipid metabolism in rats. J. Lipid Res. 20 (2), 162-174. https://doi.org/10.1016/s0022-2275(20)40628-5.

Chaïr, H., Sardos, J., Supply, A., Mournet, P., Malapa, R., Lebot, V., 2016. Plastid phylogenetics of Oceania yams (Dioscorea spp., Dioscoreaceae) reveals natural interspecific hybridization of the greater yam (D. alata). Bot. J. Linn. Soc. 180 (3), 319333. https://doi.org/10.1111/boj.12374.

Champagne, A., Bernillon, S., Moing, A., Rolin, D., Legendre, L., Lebot, V., 2010. Carotenoid profiling of tropical root crop chemotypes from Vanuatu, South Pacific. J. Food Anal. 23, 763-771. https://doi.org/10.1016/j.jfca.2010.03.021.

Champagne, A., Bernillon, S., Moing, A., Rolin, D., Legendre, L., Lebot, V., 2011. Diversity of anthocyanins and other phenolic compounds among tropical root crops from Vanuatu, South Pacific. J. Food Anal. 24, 315-325. https://doi.org/10.1016/j.jfca.2010.12.004.

Chan, Y.C., Hsu, C.K., Wang, M.F., Su, T.Y., 2004. A diet containing yam reduces the cognitive deterioration and brain lipid peroxidation in mice with senescence accelerated. Int. J. Food Sci. Technol. 39 (1), 99-107. https://doi.org/10.1046/j.09505423.2003.00751.x.

Chandrasekara, A., Kumar, T.J., 2016. Roots and tuber crops as functional foods: a review on phytochemical constituents and their potential health benefits. Int. J. Food Sci. 2016, 15 Article ID 3631647 https://doi.org/10.1155/2016/3631647.

Chen, Y.T., Lin, K.W., 2007. Effects of heating temperature on the total phenolic compound, antioxidative ability and the stability of dioscorin of various yam cultivars. Food Chem. 101 (3), 955-963. https://doi.org/10.1016/j.foodchem.2006.02.045.

Cho, J., Choi, H., Lee, J., Kim, M.S., Sohn, H.Y., Lee, D.G., 2013. The antifungal activity and membrane-disruptive action of dioscin extracted from Dioscorea nipponica. Biochim. Biophys. Acta (BBA)-Biomembr. 1828 (3), 1153-1158. https://doi.org/10.1016/j. bbamem.2012.12.010.

Cornago, D.F., Rumbaoa, R.G.O., Geronimo, I.M., 2011. Philippine Yam (Dioscorea spp.) tubers phenolic content and antioxidant capacity. Philipp. J. Sci. 140 (2), 145-152. https://doi.org/10.1016/j.foodchem.2003.12.027.

Couto, R.S., Martins, A.C., Bolson, M., Lopes, R.C., Smidt, E.C., Braga, J.M., 2018. Time calibrated tree of Dioscorea (Dioscoreaceae) indicates four origins of yams in the Neotropics since the Eocene. Bot. J. Linn. Soc. XX, 1-17. https://doi.org/10.1101/
224790.

Dilworth, L., Brown, K., Wright, R., Oliver, M., Hall, S., Asemota, H., 2012. Antioxidants, minerals and bioactive compounds in tropical staples. Afr. J. Food Sci. Technol. 3 (4), 90-98. https://doi.org/10.1002/9781118906460.ch1e.

Dueñas, M., González-Manzano, S., González-Paramás, A., Santos-Buelga, C., 2010. Antioxidant evaluation of O-methylated metabolites of catechin, epicatechin and quercetin. J. Pharmaceut. Biomed. 51 (2), 443-449. https://doi.org/10.1016/j.jpba. 2009.04.007.

Dutta, B., 2015. Food and medicinal values of certain species of Dioscorea with special reference to Assam. J. Pharmacogn. Phytochem. 3 (4), 15-18.

FAOSTAT, 2020. Retrieved January 2021 from. http://www.fao.org.

Gao, H., Kuroyanagi, M., Wu, L., Kawahara, N., Yasuno, T., Nakamura, Y., 2002. Antitumor-promoting constituents from Dioscorea bulbifera L. in JB6 mouse epidermal cells. Biol. Pharm. Bull. 25 (9), 1241-1243. https://doi.org/10.1248/bpb.25.1241.

Go, H.K., Rahman, M.M., Kim, G.B., Na, C.S., Song, C.H., Kim, J.S., et al., 2015.

Antidiabetic effects of yam (Dioscorea batatas) and its active constituent, allantoin, in a rat model of streptozotocin-induced diabetes. Nutrients 7 (10), 8532-8544. https://doi. org/10.3390/nu7105411.

Govaerts, R., Wilkin, P., Saunders, R.M.K., 2007. World Checklist of Dioscoreales, yams and their Allies. Kew Publishing, Royal Botanic Gardens, Kew, UK.

Guan, X.R., Zhu, L., Xiao, Z.G., Zhang, Y.L., Chen, H.B., Yi, T., 2017. Bioactivity, toxicity and detoxification assessment of Dioscorea bulbifera L.: a comprehensive review. Phytochem. Rev. 16 (3), 573-601. https://doi.org/10.1007/s11101-017-9505-5. Hsu, C.K., Yeh, J.Y., Wei, J.H., 2011. Protective effects of the crude extracts from yam (Dioscorea alata) peel on tert-butylhydroperoxide-induced oxidative stress in mouse liver cells. Food Chem. 126 (2), 429-434. https://doi.org/10.1016/j.foodchem.2010.11.004. Kundu, B.B., Vanni, K., Farheen, A., Jha, P., Pandey, D.K., Kumar, V., 2020. Dioscorea bulbifera L.(Dioscoreaceae): a review of its ethnobotany, pharmacology and conservation needs. S. Afr. J. Bot.. https://doi.org/10.1016/j.sajb.2020.07.028.

Lebot, V., 2020. Tropical Root and Tuber Crops: Cassava, Sweet Potato, Yams and Aroid. 2nd edition CABI, Wallingford, UK 515p.

Lebot, V., Malapa, R., Abraham, K., 2017. The Pacific yam (Dioscorea nummularia Lam.), an under-exploited tuber crop from Melanesia. Genet. Resour. Crop Ev. 64 (1), 217-235. https://doi.org/10.1007/s10722-016-0475-z.

Lebot, V., Malapa, R., Molisalé, T., 2019. Development of HP-TLC method for rapid quantification of sugars, catechins, phenolic acids and saponins to assess Yam (Dioscorea spp.) tuber flour quality. Plant Genet. Resour. 17 (1), 62-72. https://doi.org/10.1017/ s1479262118000333.

Lee, S.Y., Ganesan, P., Ahn, J., Kwak, H.S., 2011. Lactobacillus acidophilus fermented yam (Dioscorea opposita Thunb.) and its preventive effects on gastric lesion.. Food Sci. Biotechnol. 20 (4), 927. https://doi.org/10.1007/s10068-011-0128-0.

Letan, A., 1966. The relation of structure to antioxidant activity of quercetin and some of its derivatives I. Primary activity. J. Food Sci. 31 (4), 518-523. https://doi.org/10. 1111/j.1365-2621.1966.tb01897.x.

Liu, Y., Li, H., Fan, Y., Man, S., Liu, Z., Gao, W., Wang, T., 2016. Antioxidant and antitumor activities of the extracts from Chinese yam (Dioscorea opposite Thunb) flesh and peel and the effective compounds. J. Food Sci. 81, 1553-1564. https://doi.org/10. 1111/1750-3841.13322.

Ma, J., Meng, X., Liu, Y., Yin, C., Zhang, T., Wang, P., et al., 2020. Effects of a rhizome aqueous extract of Dioscorea batatas and its bioactive compound, allantoin in high fat diet and streptozotocin-induced diabetic mice and the regulation of liver, pancreas and skeletal muscle dysfunction. J. Ethnopharmacol. 259, 112926. https://doi.org/10.1016/ j.jep. 2020.112926

Markham, K.R., Mabry, T.J., 1975. Ultraviolet-visible and proton magnetic resonance spectroscopy of flavonoids. The Flavonoids. Springer, Boston, MA, pp. 45-77. Mohan, V.R., Shajeela, P.S., Jesudas, L.L., Soris, P.T., 2011. Nutritional and

antinutritional evaluation of wild yam (Dioscorea spp.). Trop. Subtrop. Agroecosyst. 14 (2), 723-730.

Ren, X., Shen, L.L., Muraoka, O., Cheng, M., 2011. Synthesis of Quercetin 3-O-[6 "-O(trans-p-Coumaroyl)]- $\beta$-D-Glucopyranoside. J. Carbohyd. Chem. 30 (3), 119-131. https://doi.org/10.1080/07328303.2011.616979.

Salehi, B., Sener, B., Kilic, M., Sharifi-Rad, J., Naz, R., Yousaf, Z., et al., 2019. Dioscorea plants: a genus rich in vital nutra-pharmaceuticals-a review. Iran. J. Pharm. Res. 18 (Suppl. 1), 68. https://doi.org/10.22037/ijpr.2019.112501.13795.

Sang, S., Cheng, X., Stark, R.E., Rosen, R.T., Yang, C.S., Ho, C.T., 2002. Chemical studies on antioxidant mechanism of tea catechins: analysis of radical reaction products of catechin and epicatechin with 2, 2-diphenyl-1-picrylhydrazyl. Bioorg. Med. Chem. Lett. 10 (7), 2233-2237. https://doi.org/10.1016/s0968-0896(02)00089-5.

Shahidi, F., Ambigaipalan, P., 2015. Phenolics and polyphenolics in foods, beverages and spices: antioxidant activity and health effects-a review. J. Funct. Food. 18, 820-897. https://doi.org/10.1016/j.jff.2015.06.018.

Shi, Z.H., Li, N.G., Tang, Y.P., Yang, J.P., Duan, J.A., 2012. Metabolism-based synthesis, biologic evaluation and SARs analysis of O-methylated analogs of quercetin as thrombin inhibitors. Eur. J. Med. Chem. 54, 210-222. https://doi.org/10.1016/j.ejmech.2012.04. 044.

Son, I.S., Kim, J.H., Sohn, H.Y., Son, K.H., Kim, J.-S., Kwon, C.-S., 2007. Antioxidative and hypolipidemic effects of diosgenin, a steroidal saponin of yam (Dioscorea spp.), on highcholesterol fed rats. Biosci. Biotech. Bioch. 71 (12), 3063-3071. https://doi.org/10. 1271/bbb. 70472 .

Song, H.J., Pan, Y.Y., Wang, W.G., Fu, L.Z., Li, H.Z., Li, H.M., Li, R.T., 2009. Studies on the chemical constituents from Rhododendron delavayi. J. Chinese Med. 32 (12), 1840-1843 Song, F.L., Gan, R.Y., Zhang, Y., Xiao, Q., Kuang, L., Li, H.B., 2010. Total phenolic contents and antioxidant capacities of selected Chinese medicinal plants. Int. J. Mol. Sci. 11 (6), 2362-2372. https://doi.org/10.3390/ijms11062362.

Walter, A., Lebot, V., 2003. Jardins d'Océanie. IRD, Paris.

Wen, X., Walle, T., 2006. Methylated flavonoids have greatly improved intestinal 
absorption and metabolic stability. Drug Metab. Dispos. 34 (10), 1786-1792. https:// doi.org/10.1124/dmd.106.011122.

Xu, M., Liu, P., Jia, X., Zhai, M., Zhou, S., Wu, B., Guo, Z., 2020. Metabolic profiling revealed the organ-specific distribution differences of tannins and flavonols in pecan. Food Sci. Nutr. 8 (9), 4987-5006. https://doi.org/10.1002/fsn3.1797.

Zhang, Y., Xu, Y., Qi, Y., Xu, L., Song, S., Yin, L., Tao, X., Zhen, Y., Han, X., Ma, X., Liu, K.,
Peng, J., 2017. Protective effects of dioscin against doxorubicin-induced nephrotoxicity via adjusting FXR-mediated oxidative stress and inflammation. Toxicology 378, 53-64 https://doi.org/10.1016/j.tox.2017.01.007. 